Jurnal Widya Sastra Pendidikan Agama Hindu, Vol 4, No. 2, 2022

ISSN: 2656-7466

\title{
PELAKSANAAN PUJA TRI SANDYA DI DESA PAKRAMAN BANYUSERI
}

\author{
I PUTU ARI SUDIADA \\ ari9sudiada@gmail.com
}

\section{ABSTRAK}

Penelitian ini merupakan jenis penelitian kulitatif yang bertujuan untuk mengetahui bagaimana bentuk, fungsi dan makna dari Pelaksanaan Puja Tri Sandya pada masyarakat di Desa Pakraman Banyuseri, apa saja hambatan yang ditemui umat dalam pelaksanaan persembahyangan Puja Tri Sandya, serta solusi apa saja yang dapat diambil agar pelaksanaan Puja Tri Sandya dapat dilaksanakan sesuai anjuran yang telah ditetapkan.

Informan ditentukan berdasarkan Purposive Sampling. Data dalam penelitian ini dikumpulkan menggunakan metode observasi dan wawancara. Analisis data meliputi: proses reduksi data, penyajian data dan verifikasi data. Hasil wawancara yang dikaji dengan Teori Religi, Teori Struktural Fungsionalisme, Teori Makna, Teori Fungsi, dan Teori Konflik bertujuan untuk mengetahui pelaksanaan Puja Tri Sandya pada masyarakat di Desa Pakraman Banyuseri.

Bentuk pelaksanaan Puja Tri Sandya di Desa Pakraman Banyuseri secara bersama-sama dalam keseharian maupun upacara keagamaan sudah berjalan dengan baik. Namun untuk pelaksanaan secara pribadi-pribadi oleh umat setiap harinya masih perlu peningkatan. Pelaksanaan ditetapkan sebanyak tiga kali dalam sehari (pagi hari, siang hari dan sore hari). Terkadang umat melaksanakan persembahyangan Puja Tri Sandya ini tidak sesuai dengan waktu tersebut, mengingat perbedaan situasi dan kondisi pekerjaan yang beragam.

Pelaksanaan Puja Tri Sandya merupakan salah satu bentuk pengamalan ajaran Bhakti Marga. Adapun pelaksanaannya memiliki beberapa fungsi, yaitu: fungsi spiritual, fungsi ritual, fungsi simbolik, fungsi harmonisasi dan fungsi sarana. Makna yang terkandung di dalamnya meliputi makna spiritual, makna religious, makna logis, makna sosial, dan makna simbolik. Solusi yang dapat diambil agar pelaksanaan persembahyangan Puja Tri sandya berjalan dengan baik sesuai dengan yang sudah ditetapkan adalah dengan memberikan pengarahan atau himbauan kepada umat, agar melaksanakan Puja Tri Sandya dengan sungguhsungguh dan mampu mengajak umat agar dapat menyesuaikan dengan situasi dan kondisi yang dimiliki.

Kata Kunci: Bentuk, Fungsi, Makna, dan Puja Tri Sandya 
Jurnal Widya Sastra Pendidikan Agama Hindu, Vol 4, No. 2, 2022

ISSN: 2656-7466

\author{
PELAKSANAAN PUJA TRI SANDYA \\ DI DESA PAKRAMAN BANYUSERI \\ OLEH: \\ I PUTU ARI SUDIADA \\ ari9sudiada@gmail.com
}

\title{
ABSTRACT
}

This research is a type of qualitative research that aims to find out how the form, function and meaning of the Tri Sandya Puja Implementation in the community in the Banyuseri Pakraman Village are, what are the obstacles encountered by the people in carrying out the Tri Sandya Puja prayer, and what solutions can be taken so that the implementation of the Puja Tri Sandya prayer can be implemented. Tri Sandya Puja can be carried out according to the recommendations that have been set.

Informants were determined based on purposive sampling. The data in this study were collected using observation and interview methods. Data analysis includes: data reduction process, data presentation and data verification. The results of the interviews that were studied using Religious Theory, Structural Functionalism Theory, Meaning Theory, Function Theory, and Conflict Theory aimed to determine the implementation of Tri Sandya Puja in the community in the Banyuseri Pakraman Village.

The form of implementing the Tri Sandya Puja in the Banyuseri Pakraman Village together in daily life and religious ceremonies has been going well. However, for individual implementation by the people every day still needs improvement. Implementation is set three times a day (morning, afternoon and evening). Sometimes people carry out the Tri Sandya Puja prayer not according to that time, given the different situations and various working conditions.

The implementation of the Tri Sandya Puja is one form of practicing the teachings of Bhakti Marga. The implementation has several functions, namely: spiritual function, ritual function, symbolic function, harmonization function and facility function. The meanings contained in it include spiritual meaning, religious meaning, logical meaning, social meaning, and symbolic meaning. The solution that can be taken so that the implementation of the Tri Sandya Puja prayer goes well in accordance with what has been determined is to provide direction or appeal to the people, to carry out the Tri Sandya Puja seriously and be able to invite the people to adapt to the situation and conditions they have.

Keywords: Form, Function, Meaning, and Tri Sandya Puja 
Jurnal Widya Sastra Pendidikan Agama Hindu, Vol 4, No. 2, 2022

ISSN: 2656-7466

\section{PENDAHULUAN}

Salah satu bagian dalam Catur Marga yang merupakan empat jalan atau cara mengamalkan ajaran agama Hindu dalam kehidupan dan dalam bermasyarakat adalah Bakti Marga. Bhakti Marga adalah usaha untuk mencapai Jagadhita dan Moksa dengan jalan sujud bakti kepada Tuhan. Dengan sujud dan cinta kepada Tuhan Pelindung dan Pemelihara semua makhluk, maka Tuhan akan menuntun seorang Bhakta, yakni orang yang cinta, bakti, dan sujud kepada-Nya untuk mencapai kesempurnaan. Dengan doa mohon perlindungan dan ampunan atas dosa-dosa yang pernah dilakukan serta mengucap syukur atas perlindunganNya. Bahkan terkadang ketika kita malaksanakan persembahan atau berdoa secara rutin maka kian hari cinta baktinya kepada Tuhan makin mendalam hingga Tuhan menampakkan diri di hadapan bhakta itu. Tuhan memelihara dan melindungi orang yang beriman itu, supaya hidupnya tetap tenang dan tentram. Jalan yang utama untuk memupuk perasaan bakti ialah rajin menyembah Tuhan dengan hati yang tulus iklas, seperti melaksanakan Puja Tri Sandya yaitu sembahyang tiga kali dalam sehari, pagi, siang dan sore hari dan bersembahyang pada perayaan hari suci lainnya.

Sebagai umat Hindu sudah sepatutnya wajib melaksanakan persembahyangan Puja Tri Sandya tiga kali dalam sehari, sesuai dengan yang sudah dianjurkan. Sembahyang rutin ini diamanatkan dalam kitab suci Weda dan sudah dilaksanakan sejak ribuan tahun yang lalu. Bila kita tidak tekun melaksanakan hal ini berarti umat tidak secara sungguh-sungguh mengamalkan ajaran yang terkandung didalam kitab suci Weda.

Melaksanakan persembahyangan Puja Tri Sandya tiga kali dalam sehari memang tidak semua umat yang dapat melaksanakannya, terutama hanya dapat dilaksanakan oleh para sulinggih maupun orang suci yang kita kenal dengan istilah Nyurya Sewana, yaitu melaksanakan pemujaan ketika matahari terbit, matahari berada tepat tegak di atas langit, dan ketika matahari terbenam dengan tujuan untuk memuja Dewa Surya sebagi entitas Tuhan yang paling mulia dan medoakan alam semesta beserta isinya serta menghubungkan diri dengan Sang Pencipta. Bagi umat yang biasa tentunya pelaksanaan Puja Tri Sandya tiga kali dalam sehari tentunya tidak dapat terpenuhi mengingat ada banyak hambatan yang dialami, hambatan itu antara lain: karena kurang memahami makna yang terkandung dalam melaksanakan Puja Tri Sandya, karena enggan atau malas sebab tidak dibiasakan, bahasanya tidak atau kurang dipahami, dan hambatan yang paling sulit adalah masalah pekerjaan.

Ketika mempelajari hambatan-hambatan tersebut, umat Hindu patut mencari solusi yang baik agar masyarakat dapat memenuhi sadananya sendiri sebagai umat Hindu yang harus melaksanakan Puja Tri Sandya tepat sebanyak tiga kali dalam sehari. Upaya yang dapat dilakukan supaya bisa mengamalkan kewajiban itu adalah umat sewajarnya harus menumbuhkan tekad di dalam diri bahwa masyarakat mampu untuk melaksanakan hal itu. Selanjutnya coba pelajari dan hafalkan tiap-tiap kata dalam mantram yang digunakan dalam Tri Sandya. Upaya yang lain adalah dalami makna dari setiap mantra yang ada didalamnya, seperti mantra Gayatri pada bait pertama dalam Puja Tri Sandya, merupakan mantram yang sangat disucikan sebagai umat Hindu. Seperti yang diamanatkan dalam kitab Atharwa Weda, mantram Gayatri atau Gayatri mantram adalah Wedamata atau ibu dari segala mantram Weda yang dapat memberikan perlindungan, keselamatan, kegembiraan, kebahagiaan dan yang lainnya. 
Desa Banyuseri memang sangat unik diantara desa yang masuk Baliaga hanya desa Banyuseri yang mulai mengalami perkembangan terutama di bidang budaya dan keagamaan, namun ternyata dibalik semua itu ada berbagai konteks permasalahan terutama pada pelaksanaan Puja Tri Sandya. Banyak tokoh yang merasa keberatan bila Puja Tri Sandya ini dilaksanakan dengan pengeras suara karena anggapan mereka berdoa ataupun sejenisnya cukup hanya di dalam hati saja tanpa harus mengeluarkan kata. Namun dalam upacara Panca Yadnya pelaksanaan Puja Tri Sandya ini wajib menggunakan pengeras suara agar masyarakat kompak mengucapkan mantram demi mantram.

\section{METODE PENELITIAN}

Ada beberapa metode yang digunakan dalam menuntaskan penelitian ini, yaitu: metode penentuan informan, metode pengumpulan data dan metode analisis data. Dalam menentukan informan digunakan teknik purposive sampling dan snowball sampling. Teknik purposive sampling adalah teknik penentuan informan (sumber data) dengan cara pilih memilih dengan pertimbangan tertentu, misalnya orang tersebut yang dianggap paling tahu tentang obyek yang diteliti. Sedangkan snowball sampling adalah teknik penentuan informan (sumber data) yang jumlah semakin bertambah apabila dipandang perlu dan akan dihentikan apabila sudah dipandang cukup oleh peneliti. Terkait dengan hal ini, informan yang dipilih adalah tokoh-tokoh masyarakat desa Banyuseri, masyarakat Desa Banyuseri.

Ada dua teknik yang digunakan dalam mengumpulkan data, yaitu wawancara terstrktur dan pencatatan dokumen. Wawancara berstruktur dipilih dengan alasan peneliti akan tervokus pada data yang diperlukan pada data yang diperlukan dalam penelitian yang dilaksanakan, sehingga hal-hal itulah yang ditanyakan pada informan. Pencatatan dokumen digunakan sebagai pelengkap data yang diperoleh dari wawancara. Pencatatan yang dilakukan dalam penelitian ini baik pada saat wawancara maupun mencatat dari sumber-sumber tertulis yang ada baik berupa peraturan-peraturan tertulis, kitab-kitab yang terkait dengan Sampi Gerumbungan. Selanjutnya digunakan teknik triangulasi, yaitu menggabungkan dari berbagai teknik pengumpulan data dan sumber data yang telah ada. Teknik ini digunakan dengan alasan di samping dapat mengumpulkan data juga sekaligus dapat menguji kredibilitas data. Menggunakan teknik triangulasi dalam pengumpulan data akan memperoleh data yang lebih konsisten, tuntas, dan pasti, serta akan lebih meningkatkan kekuatan data (Sugiyono, 2007:241).

Untuk dapat merumuskan hasil penelitian, maka data yang didapat harus dianalisis dengan metode analisis data. Dalam menganalisis data digunakan metode analisis data kualitatis dengan tiga tahap, yaitu menreduksi data, mendisplay data dan menarik simpulan dan verifikasi.

a. Reduksi Data

Data yang diperoleh berupa diskrepsi dirangkum, dipilih hal-hal yang pokok atau hal-hal berkaitan dengan masalah yang diteliti. Data yang telah direduksi akan memberikan gambaran yang lebih tajam dari hasil wawancara dan pengamatan yang telah dilaksanakan.

b. Display Data

Data yang didapat dalam pengumpulan data tentu jumlah sangat banyak, sehingga ada tata yang tidak sesuai dengan data yang dibutuhkan, sehingga ada yang harus dibuang atau disihkan. Dengan menyisihkan data yang tidak diperlukan akan memudahkan menarik simpulan. Hal ini dapat dilakukan dengan 
Jurnal Widya Sastra Pendidikan Agama Hindu, Vol 4, No. 2, 2022

ISSN: 2656-7466

membuat model atau grafik sehingga keseluruhan data dan bagian-bagian dapat dipetakan dengan jelas.

c. Kesimpulan dan Verifikasi

Data yang sudah tersusun dalam pola atau grafik tertentu kemudian disimpulkan sehingga makna data bisa ditemukan. Dan simpulan ini baru bersifat sementara dan umum. Agar lebih mendalam perlu data baru sebagai pembanding atau pengujian terhadap simpulan yang diambil, sehingga kebenaran simpulan jauh lebih akurat.

\section{HASIL DAN PEMBAHASAN}

Menurut Kelian Desa Pakraman Banyuseri, Bapak I Made Sumatra menyatakan bahwa pelaksanaan Puja Tri Sandya pada masyarakat di Desa Pakraman Banyuseri terlaksana sesuai dengan tiga waku yang sudah ditetapkan, yaitu: waktu pagi hari, waktu siang hari dan waktu sore hari. Pelaksanaan Puja Tri Sandya biasanya dilaksanakan terutama di Pura Desa.

Setiap hari sesuai tiga waktu tersebut, umat datang ke Pura untuk melaksanakan Persembahyangan Puja Tri Sandya sesuai dengan porsi waktu yang dimiliki sehingga tidak mengganggu aktivitas yang rutin dilakukan. Selain itu, Puja Tri Sandya juga terlaksana dalam waktu periodik, seperti: saat hari Purnama dan Tilem, saat hari raya besar Hindu (Galungan, Kuningan, Pagerwesi, Saraswati, Nyepi, Siwaratri) dan saat piodalan baik piodalan yang berlangsung di Pura Dalem dan Pura Desa maupun piodalan yang dilaksanakan di Sanggah Dadia keluarga masingmasing keluarga.

Sekretaris Desa Pakraman Banyuseri, Bapak Putu Pasmika Giri menyatakan bahwa Puja Tri Sandya yang dilaksanakan secara rutin setiap hari selama tiga kali (pagi, siang dan sore) di Desa Banyuseri yang bertempat di Pura Desa. adapun pelaksanaannya dimulai sejak tahun 2009. Awalnya, umat Hindu bersama-sama datang ke Pura untuk mengikuti persembahyangan Puja Tri Sandya ini, yang ditandai dengan bunyi gamelan yang dibunyikan 30 menit sebelum waktu pelaskanaannya. Namun, mengingat beragamnya akivitas warga masyarakat masing-masing maka dibuatlah pembagian waktu sehingga umat bisa melaksanakan persembahyangan ke Pura sesuai kesepakatan waktu. Untuk pelaksanaan secara bersama-sama juga dilaksanakan ketika piodalan berlangsung di Pura dan sanggah dadia, serta saat perayaan hari besar Hindu. Adapun persembahyangan bersama ini akan dipimpin oleh seorang manggala dari pengurus atau prajuru desa setempat.

Menurut Ketua Dadia Arya Kepakisan Desa Pakraman Banyuseri Bapak Putu Sidarta Gautama ( nama panggilan Bapak Sigo) menyatakan bahwa pelaksanaan Puja Tri Sandya di Desa pakraman Banyuseri berlangsung tiga kali sehari. Hal ini terlihat disaat pelaksanaannya, baik pagi, siang maupun sore hari. Ada saja umat yang datang ke Pura bersama pemimpin yang memang ditugaskan untuk melaksanakan persembahyangan dimaksud. Walaupun jumlah yang hadir tidak begitu banyak, namun tidak mengurangi kekhusyukkan dan keheningan dalam melaksanakan persembahyangan Puja Tri Sandya di Pura. Untuk waktu tertentu pun juga dilaksanakan secara bersama-sama, seperti saat piodalan maupun perayaan hari raya Hindu.

Ditegaskan oleh tokoh masyarakat, Made Karyawan bahwa pelaksanaan Puja Tri Sandya berlangsung sesuai waktu yang ditetapkan, yaitu tiga kali sehari yang dilaksanakan di pura. Puja Tri Sandya dilaksanaan secara bersama-sama oleh umat walaupun tidak semua krama yang terlibat di dalamnya. Pelaksanaan 
persembahyangan ini juga dilaksanakan ketika piodalan berlangsung dan ketika perayaan hari besar Hindu. selain di pura, di masing-masing sanggah dadia juga dilaksanakan ketika piodalan dan hari raya Hindu. Namun pelaksanaan secara pribadi-pribadi masih sangat minim. Hal itu pun tergantung dari waktu yang dimiliki dan situasi serta kondisi.

Menurut Bendahara Desa Pakraman Banyuseri, Bapak Putu Astawa menyatakan bahwa pelaksanaan Puja Tri Sandya di Desa Pakraman Banyuseri berjalan sesuai himbauan Kemterian Agama RI Kabupaten Buleleng, yaitu dilaksanakan tiga kali sehari, yang dilaksanakan secara bersama-sama di Pura Dalem. Namun, di desa ini pelaksanaannya di Pura Desa karena berdasarkan pertimbangan "Sima Drsta Desa Banyuseri". Umat datang ke Pura ketika sudah dibunyikan pertanda berupa Gamelan lewat pengeras suara, Kendatipun tidak semua umat mengikutinya, Puja Tri Sandya tetap berlangsung. Umat yang tidak datang ke pura memiliki anggapan atau keyakinan bahwa untuk melaksanakan persembahyangan Puja Tri Sandya tidak mesti harus berlokasi di Pura, namun bisa dimana saja (termasuk di rumah), asalkan dilakukan dengan penuh ketulusan dan kekhusukan. Ketika piodalan maupun perayaan hari raya Hindu baik di pura maupun di sanggah dadia juga dilaksanakan persembahyangan Puja Tri sandya, setelah itiu dilanjutkan dengan Puja Kramaning Sembah.

Menurut Jero mangku Ketut Winasih selaku koordinator bagian Juru Sapuh Pura Sad Khyangan Desa, bahwa pelaksanaan Puja Tri Sandya sehari-hari di Desa Pakraman Banyuseri terlaksana tiga kali sehari sesuai dengan waktu yang dianjurkan, yaitu pagi hari, siang hari dan sore hari. Adapun pelaksanaannya dipimpin oleh para manggala yang ditugaskan secara bergantian. Krama Desa Pakraman datang sendiri ke Pura sesuai dengan jadwal yang telah ditetapkan sebelumnya. Selain itu, pelaksanaan Puja Tri Sandya pada perayaan hari besar Hindu juga dilaksanakan, seperti Purnama dan Tilem, Pagerwesi, Saraswati, Galungan dan Kuningan serta yang lainnya, dilaksanakan setelah nganteb Aturan Desa yang diikuti oleh krama seluruhnya. Jika krama banyak yang hadir dan tempat tidak mencukupi maka pelaksanaannya dilakukan secara bergantian.

Menurut wakil kelian Banjar Adat Desa Pakraman Banyuseri, Bapak I Gede Suardana menyatakan bahwa pelaksanaan Puja Tri sandya di Desa Pakraman Banyuseri berlangsung setiap hari, yaitu tiga kali dalam sehari, pada pagi hari, siang hari dan sore hari. Selain itu juga dilaksanakan secara bersama-sama pada saat Piodalan dan perayaan hari besar Hindu lainnya. Kendati demikian, secara pribadi masing-masing umat masih sangat jauh pelaksanaanya, mengingat kegiatan persembahyangan ini bersifat pribadi sesuai dengan kondisi serta situasi yang dialami oleh umat tersebut.

Berdasarkan pemaparan hasil wawancara di atas maka dapat disimpulkan bahwa pelaksanaan Puja Tri Sandya Di Desa Pakraman Banyuseri sudah terlaksana dengan baik secara bersama-sama baik untuk yang sehari-hari maupun saat piodalan serta perayaan hari besar Hindu. Umat secara bersama-sama melaksanakan persembahyangan Puja Tri Sandya yang dipimpin oleh Manggala yang sudah ditugaskan secara bergantian untuk setiap harinya dan dipimpin oleh seorang prajuru Desa Pakraman maupun Banjar adat tatkala piodalan dan perayaan hari besar Hindu. Namun demikian, pelaksanaan Puja Tri Sandya yang dilaksanakan secara pribadi oleh masing-masing umat masih sangat jauh dari harapan, dikarenakan situasi dan kondisi umat yang berbeda-beda. Pelaksanaan ini tidak dapat terkontrol dengan baik karena pelaksanaannya tergantung dari niat dan kesadaran dari umat itu sendiri. 
Puja Tri Sandya ini merupakan doa dalam mantra yang dilantunkan untuk menghubungkan diri dengan Tuhan sebagai Sang Pencipta. Doa dimaksudkan di sini berhubungan sistem religi. Ada lima bagian dari Sistem Religi ini yaitu: Sistem Kepercayaan, Sistem Ritual, waktu atau tempat ritual, peralatan ritual dan umat atau peserta ritual.

Bentuk pelaksanaan Puja Tri Sandya adalah doa yang dilantunkan dalam persembahyangan yang terstruktur, dimana diawali dengan persiapan, pelaksanaan atau inti persembahyangan dan diakhiri dengan penutup. Berikut runtutan pelasksanaan persembahyangan Puja Tri Sandya sebagai berikut.

a. Kata "Om atau Om Kara" merupakan lambang dari Tuhan yang terdiri dari tiga huruf suci yang merupakan lambang dari Tiga Dewa yang utama, yang biasa disebut dengan Tri Murti. Tri Murti terdiri dari Dewa Brahma sebagai Pencipta yang dilambangkan dengan huruf suci " $A$ ", Dewa Wisnu sebagai Pemelihara yang dilambangkan dengan huruf suci " $U$ ", dan Dewa Shiwa sebagai Pelebur yang dilambangkan dengan huruf suci " $M$ ". Jadi $O m$ merupakan gabungan dari ketiga huruf suci yang melambangkan ketiganya menjadi satu untuk melambangkan Tuhan atau Hyang Widhi.

b. Kata "Bhur, Bwah dan Swah" yang merupakan lambang dari tiga alam yang dikenal dalam konsep Hindu. Bhur adalah alam bawah, Bwah adalah alam tengah, dan Swah adalah alam atas. Alam bawah ini dimaksudkan sebagai tempat berdiamnya mahkluk yang rendah dan memiliki tingkat keutamaan yang rendah. Untuk alam tengah, merupakan alam tempat dimana mansia tinggal, dengan segala misteri kehidupan yang ada dan harus dijalani oleh umat manusia serta para binatang dan tumbuh-tumbuhan yang hidup berdampingan antara yang satu dengan yang lainnya, saling bergantung dan saling bersinergi antara ketiganya. Yang terakhit adalah alam atas. Alam ini merupakan tempat bagi para Dewa Dewi, para bidadari dan mahkluk lain yang memiliki tingkat keutamaan tinggi.

c. Kata "Narayano Na Dvityyo Astikascit" yang terdapat pada bait ke dua dari mantra Puja Tri Sandya memiliki arti "sucilah Dewa Narayana, la hanya satu tak ada yang kedua". Hal ini menyatakan bahwa penggunaan simbol bahwa Tuhan itu satu tak ada yang kedua, walaupun banyak perwujudan Beliau yang disebut dengan banyak nama yang disesuaikan dengan tugas dan fungsinya.

\section{KESIMPULAN \& SARAN Simpulan}

Berdasarkan uraian di atas berikut ini akan disajikan simpulan dan berdasarkan simpulan tersebut disampai beberapa saran sebagai berikut.

Persembahyangan Puja Tri Sandya merupakan salah satu wujud Bhakti kehadapan Hyang Widhi atas segala limpahan karunia dan rahmat yang telah diberikan kepada umat. Hal ini dapat menjadi wujud ungkapan rasa terima kasih yang murni serta suci yang dilaksanakan setiap hari sebanyak tiga kali dalam kegiatan sehari-hari atau pada hari-hari tertentu, seperti pada saat hari raya yang jatuh berdasarkan Sasih, pawukon dan berdasarkan hari.

\section{Saran}

Berdasarkan simpulan yang telah diuraikan, maka diberikanlah beberapa saran terkait dengan "Pelaksanaan Puja Tri Sandya Pada Masyarakat Di Desa Pakraman Banyuseri", yaitu: 
1. Diharapkan dengan diketahuinya uungsi dan makna pelaksanaan persembahyangan Puja Tri Sandya ini umat secara umum akan lebih meningkatkan aktivitas keagamaan yang dilakukan baik secara waktu periodik tertentu maupun setiap hari, terutama pada pelaksanaan persembahyangan Puja Tri Sandya sebagai wuud ungkapan rasa terima kasih dan rasa syukur yang tinggi kehadapan Tuhan atau Ida Sang Hyang Widhi.

2. Bagi pihak terkait, yaitu pihak Kementerian Agama khususnya di Kabupaten Buleleng dan tim penyuluh yang ada di Desa Pakraman yang berkerja sama dengan perangkat Desa Pakraman dan yang lainnya agar lebih mengintensifkan kegiatan-kegiatan yang dapat meningkatkan pemahaman serta pengertian mengenai fungsi dan makna serta tujuan dari Pelaksanaan persembahyangan Puja Tri sandya ini agar umat yang ada di Desa Pakraman Banyuseri lebih meningkat mengenai pelaksanaan persembahyangan tersebut.

3. Bagi para umat yang ada di Desa Pakraman Banyuseri agar lebih dalam lagi mempelajari pustaka-pustakka keagamaan untuk lebih banyak memahami serta mengerti mengenai fungsi dan makna serta tujuan dari pelaksanaan Puja Tri Sandya baik yang dilaksanakan pada hari-hari tertentu maupun setiap hari

\section{DAFTAR PUSTAKA}

Abdulchaer. 1994. Teori Makna. Jakarta: Bina Kasih

Anandha Kusuma, Sri Rsi. 1992. Mantram Puja tri sandya. Kelungkung: Arsip Daerah

Ananda Kusuma, Sri Rsi. 2005. Puja Tri Sandya dan Mantram. Kelungkung: Arsip Daerah

Arikunto. 1999. Metode Penelitian Kualitatif. Jakarta: Ui Press

Azwar. 1986. Pengujian Keabsahan Data. Bandung: Buwana Pustaka

Djumur, Muh Surya. 2013. Metode Penelitian Kualitatif. Jakarta: Ui Press

Durkheim. 1879. Teori Fakta Social. Jakarta: Ui Press

http://bali.kemenag.go.id/index.php?a=berita\&id=120861. Diakses pada 24 Februari 2016

http://id.wikipedia.org/wiki/Konsep. Diakses pada 15 Juni 2015

https://id.wikipedia.org/wiki/Sembahyang. Diakses pada 15 Juni 2015

http://viewiani.blogspot.co.id/2014/02/kesakralan-mantram-tri-sandya.html. Diakses pada 24 februari 2016

http://yatrakencana.blogspot.co.id/2016/05/nama-i-putu-yatrakencananim2015103003.html. Diaskses pada 13 Juni 2016

Ichal, Muhammad Faisal.2013. Analisis Data Dalam Penelitian Kualitatif (Buku

Ajar Part 5).Tersedia pada http://ichaledutech.blogspot.com. Diakses pada 10 Juli 2015

Ichal. 2013. Metode Penelitian Kualitatif. Jakarta: Ui Press

lqbal. 2002. Metode Penelitian. Jakarta: Bhuawana IImu Popular

Kaplan. 1999. Teori Structural Fungsional. Bandung: Widya Darma

Karl Marx. 1883. Teori Social dan Fakta Sosial. Jakarta: Ui Press

Koentjaraningrat. 1990. System Religi. Jakarta: Pustaka Zahra

Koentjaraningrat. 1983. Penelitian Kualitatif. Jakarta: Pustaka Zahra

Koentjaraningrat. 2010. Sejarah Teori Antropologi. Jakarta : Ui Press

Koentjaraningrat,1985. Sejarah Teori Antropologi. Jilid I. Jakarta: Ui Press

Koentjaraningrat, 1985. Teori Antropologi. Jakarta: Ui Press

Mansoer Pateda. 2001. Teori Makna. Jakarta: Bina Kasih

Miles, Huberman. 1984. Metode Penelitian Kualitatif. Jakarta: Ui Press 
Jurnal Widya Sastra Pendidikan Agama Hindu, Vol 4, No. 2, 2022 ISSN: 2656-7466

Moleong. 2006. Penelitian Kualitatif. Bandung: Buwana Pustaka Nata, Jro. 2012. Doa dan Sesontengan. Singaraja: Gedung Kertya Nata, Jro. 2010. Mantram Gayatri. Singaraja: Gedung Kertya Netra. 1974. Metodologi Penelitian. Jakarta: Bhuana IImu Populer Nguraha. 2006. Catur Marga. Surabaya: Paramita Surabaya. Nursalam. 2003. Metode Penelitian Kualitatif. Jakarta: Ui Press Okieshcatzie. 2007. System Kepercayaan. Jakarta: Balai Pustaka Patton. 1990. Metode Penelitian Kualitatif. Jakarta: Ui Press PHDI, 1991. Tri Sandya. Jakarta: Arsip Daerah Pidarta. 2002. System Kepercayaan. Jakarta: Balai Pustaka Pip Jones. 2010. Pengantar Teori-Teori Social. Yogyakarta: Yayasan Pustaka Obor Indonesia

Prasetyo. 2013. Reduksi Data. Jakarta: Bhuawana IImu Popular Ritzer, George. 2008. Teori Sosiologi. Jakarta: Kencana Santra. 1999. Wariga. Surabaya: Paramita Sindung Haryanto. 2012. Spektrum Teori Sosial . Jakarta: Perpustakaan Unilak Soerjono Soekanto. 2009. Interaksi Sosial. Jakarta: Primagama Spradley. 2013. Metode Penelitian Kualitatif. Jakarta: Ui Press Sudharta. 2010. Wariga. Surabaya: Paramita Surabaya. Sudirga,Dkk. 2002. Mantra. Surabaya: Paramita Sugiono. 2005. Penelitian Kualitatif. Bandung: Widya Darma Suhardana. 2008. Sembahyang Dan Doa. Surabaya: Paramita Sukadji. 2000. Penelitian Kualitatif. Bandung: Widya Darma Sukartha, Dkk. 2002. Doa Dan Mantra. Surabaya: Paramita Sumerta. 2016. Pelaksanaan Puja Tri Sandya Di Desa Sukasada. Perpustakaan Suparmi. 1990. Persembahyangan. Surabaya : Paramita Daerah: Widya Dharma Triguna. 1997. Teori Fungsionalisme. Jakarta: Balai Pustaka Trisna. 1989 Sembahyang Tiga Kali Sehari. Surabaya: Paramita Usman. 2004. Teori Structural Fungsional. Bandung: Widya Darma Wilansari, Dewi. 2009. Sosiologi (Konsep Dan Teori). Bandung: Pt Refika Aditama Wirawan, Ida Bagus. 2012. Teori-Teori Sosial Dalam Tiga Paradigma. Jakarta: Perpustakaan Nasional RI 